\title{
Quantitative three dimensional echocardiography in patients with pulmonary hypertension and compressed left ventricles: comparison with cross sectional echocardiography and magnetic resonance imaging
}

Howard D Apfel, Zhanqing Shen, Aasha S Gopal, Venturella Vangi, David Solowiejczyk, Karen Altmann, Robyn J Barst, Lawrence M Boxt, Lindsey D Allan, Donald L King

\begin{abstract}
Objective-To evaluate the accuracy of quantitative three dimensional echocardiography in patients with deformed left ventricles

Design-Three dimensional and cross sectional echocardiographic estimates of left ventricular volume and ejection fraction were prospectively compared to those obtained from magnetic resonance imaging.
\end{abstract}

Setting-Echocardiography laboratory of a university hospital.

Patients-26 patients (9 months to 42 years, median age 11 years) with pulmonary hypertension and fixed reversal of normal interventricular septal curvature.

Main outcome measures-Left ventricular end diastolic and end systolic volumes and ejection fraction.

Results-Three dimensional echocardiographic comparison to magnetic resonance imaging (MRI) yielded $r$ values of 0.94 and 0.87 with a bias of -6.9 (SD 6.9) $\mathrm{ml}$ and $-16(11.2) \mathrm{ml}$ for systolic and diastolic volumes respectively. Interobserver variability was minimal $(8 \cdot 3 \%$ and $7 \cdot 6 \%$ respectively). Cross sectional echocardiography gave correlation coefficients of 0.62 and 0.80 and bias of 3.1 $(14 \cdot 1) \mathrm{ml}$ and $16 \cdot 3(18 \cdot 3) \mathrm{ml}$ for systolic and diastolic volumes respectively. Ejection fraction by three dimensional echocardiography also had closer agreement with MRI (bias $=1 \cdot 1(7 \cdot 7) \%$ ) than cross sectional echocardiography (bias = $4 \cdot 4$ (13.9)\%).

Conclusions-Three dimensional echocardiography provides reliable estimates of left ventricular volumes and ejection fraction, comparable to magnetic resonance imaging in pulmonary hypertension patients with compressed ventricular geometry. Because it eliminates the need for geometric assumptions it shows closer agreement with magnetic resonance imaging in that setting than cross sectional echocardiography.

(Heart 1996;76:350-354)
Keywords: three dimensional echocardiography; cross sectional echocardiography; left ventricular deformity; pulmonary hypertension.

Accurate measurement of left ventricular volume and function is important in the management of patients with congenital heart disease. Nonetheless, quantitative ventricular assessment is often difficult to accomplish in these patients because ventricular geometry is frequently distorted and does not conform to the uniform shapes prescribed by conventional cross sectional imaging volume algorithms. Previous studies have shown that quantitative cross sectional echocardiographic techniques, suboptimal in non-distorted ventricles, ${ }^{1}$ become increasingly inaccurate with advancing degrees of ventricular distortion..$^{2-6}$ Magnetic resonance imaging has been suggested as an alternative method that provides accurate volume and functional analysis without the need for geometric assumptions, ${ }^{7-9}$ but is limited by expense, patient discomfort, and the prolonged time needed for acquisition and analysis.

Recently, three dimensional echocardiographic methods have been developed to overcome the major limitations of cross sectional echocardiography and improve upon the latter's quantitative reliability. ${ }^{10-25}$ Volume and functional assessment by three dimensional echocardiography in a selected group of patients with compressed ventricular geometry, however, has not been reported. Therefore, this study was undertaken to compare estimation of left ventricular volume and ejection fraction by three dimensional and cross sectional echocardiography to determinations by magnetic resonance imaging (MRI) in patients with pulmonary hypertension and markedly distorted left ventricular geometry.

\section{Methods}

PATIENTS

Twenty eight consecutive patients with pulmonary hypertension referred between July 1993 and April 1995 for pulmonary vasodilator treatment were studied. The diagnosis of pulmonary hypertension was made at catheterisation if pulmonary artery (PA) pressure at rest was raised (mean PA pressure greater than 20 $\mathrm{mm} \mathrm{Hg}$ ) and pulmonary wedge pressure was normal. The mean pulmonary artery to mean 

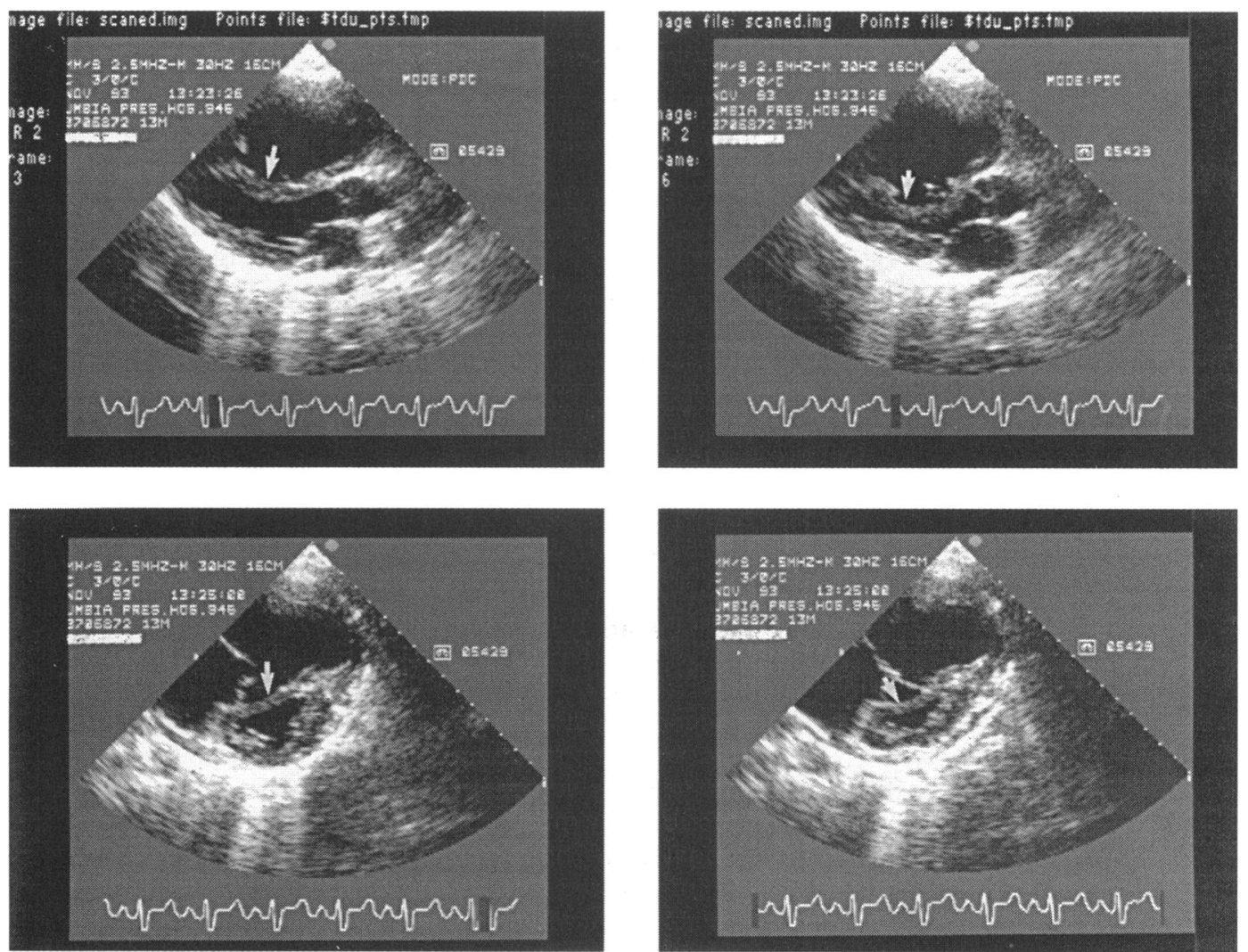

Figure 1 Parasternal long axis reference images (above) and short axis data images (below) illustrate the fixed reversal of normal septal curvature (arrows) present in the study patients throughout the cardiac cycle. A diastolic frame is illustrated on the left and a systolic frame on the right.

systemic arterial blood pressure ratio for the group was $0.75 \pm 0.35$ (median 0.67 , range 0.40 to $1 \cdot 5$ ). All patients showed evidence of compressed cardiac anatomy as defined by fixed reversal of normal septal curvature (fig 1). All patients or a legal guardian gave informed consent in accordance with Columbia University's institutional review board.

All patients underwent examination by cross sectional and three dimensional echocardiography and MRI. Only two patients (ages 2 and 3 years) required sedation with chloral hydrate (50 $\mathrm{mg} / \mathrm{kg}$ ) before each of the echocardiographic studies. Two patients were excluded due to inadequate echocardiographic images. Of the 26 patients enrolled, 13 underwent three dimensional echocardiographic examination within 12 hours, nine patients within 36 hours, and four patients within 72 hours of MRI. Twenty two out of the 26 enrolled patients also underwent a conventional cross sectional echocardiographic examination within one to six days of MRI. Three of the 22 studies were considered technically inadequate for analysis and were excluded. No change in patient clinical status, haemodynamic status, or medical regimen occurred during the period of data acquisition. The final study group comprised 18 females and eight males; 17 of the 26 patients were less than 13 years of age (median age 11.6 years, range 9 months to 42 years).

\section{THREE DIMENSIONAL ECHOCARDIOGRAPHY} Instrumentation

The features of our three dimensional echocardiographic system have been described previously. ${ }^{19}$ Briefly, an acoustic spatial locator
(Model GP 8-3D, Science Accessories Corporation, Stratford, CT, USA) and personal computer (Model 4DX-33V, Gateway 2000, North Sioux City, South Dakota, USA) are linked to a conventional cross sectional echocardiograph (Model 77020AC, HewlettPackard Corporation, Andover, MA, USA). ECG gated real time echocardiographic images are transmitted to the personal computer, digitised, and stored together with their spatial coordinate data in cine-loop format for future retrieval and analysis.

\section{Image acquisition using the line of intersection} display

The display of the line of intersection in a reference image is used by the operator to guide positioning the real time short axis images during acquisition of a dataset for volume computation. By using the display, the operator is able to assure that the short axis images define the end planes accurately representing the ventricle. The short axis images are spaced appropriately from the inferior surface of the aortic valve throughout the body of the left ventricle to the apex. For computation of left ventricular volume, a typical dataset is composed of 7-10 short axis images. The time currently required for imaging and acquisition of each data set is approximately 6-8 $\mathrm{min}$.

Surface reconstruction and volume computation A polyhedral surface reconstruction algorithm has been adapted for left ventricular volume computation using the traced endocardial borders of each short axis image. End diastolic (onset of QRS complex) and end systolic 
(smallest chamber dimension) video frames from each acquired cine-loop are selected for off-line boundary tracing. Volumes between all boundaries are in turn calculated and summed to yield the total volume of the ventricle. Thus end diastolic and end systolic volumes are computed from their respective datasets and ejection fraction is calculated from these values. After tracing is completed, the processing time required to create the three dimensional model and generate volumes for a given patient is less than $1 \mathrm{~min}$.

\section{Procedure}

A single three dimensional echocardiographic examination was performed by one of two examiners on all patients. Two observers blinded to the results of the MRI independently selected end diastolic and end systolic video frames and manually traced the respective endocardial boundaries. Tracing of the endocardium was performed on the white side of the black-white boundary. Papillary muscles were included as part of the cavity volume when they were noted to be discontinuous with the myocardium. The time required for tracing endocardial borders was approximately $1 \mathrm{~min}$ per boundary, or a total of 8-9 $\mathrm{min}$ for each dataset.

\section{MAGNETIC RESONANCE IMAGING}

The MRI examination was carried out using a $1.5 \mathrm{~T}$ superconducting magnet (Signa, General Electric, New York, USA). All children under eight years of age were sedated with chloral hydrate (five patients). A coronal image was first obtained through the aortic valve and left ventricle. Then a series of short axis ECG gated images was obtained at 16 phases of the cardiac cycle normal to the line drawn between the centre of the aortic valve and the left ventricular apex using gradient

Table 1 Comparison of left ventricular volumes by three dimensional and cross sectional echocardiography to magnetic resonance imaging

\begin{tabular}{lllrrr}
\hline Method & $n$ & $r$ & SEE & $\begin{array}{l}\text { Bias } \\
\text { (mean of } \\
\text { differences) }\end{array}$ & $\begin{array}{l}\text { Limits of } \\
\text { agreement } \\
( \pm 2 S D)\end{array}$ \\
\hline End diastolic volume: & & & & & \\
3D (OBS 1) & 26 & 0.94 & $9.1 \mathrm{ml}$ & $19.1 \mathrm{ml}$ & $29.2 \mathrm{ml}$ \\
3D (OBS 2) & 26 & 0.93 & $8.7 \mathrm{ml}$ & $15.7 \mathrm{ml}$ & $22.8 \mathrm{ml}$ \\
2D (OBS 1) & 19 & 0.80 & $18.5 \mathrm{ml}$ & $16.3 \mathrm{ml}$ & $36.6 \mathrm{ml}$ \\
2D (OBS 2) & 19 & 0.60 & $33.2 \mathrm{ml}$ & $5.7 \mathrm{ml}$ & $64.8 \mathrm{ml}$ \\
End systolic volume: & & & & & \\
3D (OBS 1) & 26 & 0.85 & $6.4 \mathrm{ml}$ & $6.5 \mathrm{ml}$ & $14.7 \mathrm{ml}$ \\
3D (OBS 2) & 26 & 0.87 & $6.5 \mathrm{ml}$ & $7.2 \mathrm{ml}$ & $13.7 \mathrm{ml}$ \\
2D (OBS 1) & 19 & 0.62 & $14.2 \mathrm{ml}$ & $3.1 \mathrm{ml}$ & $28.2 \mathrm{ml}$ \\
2D (OBS 2) & 19 & 0.39 & $15.2 \mathrm{ml}$ & $1.3 \mathrm{ml}$ & $33.4 \mathrm{ml}$ \\
\hline
\end{tabular}

OBS 1, observer one; OBS 2, observer two; $r$, correlation coefficient; SEE, standard error of the estimate; 2D, cross sectional echo (biplane summation of discs method); 3D, three dimensional echocardiography.

Table 2 Comparison of left ventricular ejection fraction by three dimensional and cross sectional echocardiography to magnetic resonance imaging

\begin{tabular}{lllll}
\hline Method & $n$ & $\begin{array}{l}\text { Inter- } \\
\text { observer } \\
\text { variability }\end{array}$ & $\begin{array}{l}\text { Bias } \\
\text { (mean of } \\
\text { differences) }\end{array}$ & $\begin{array}{l}\text { Limits of } \\
\text { agreement } \\
( \pm 2 S D)\end{array}$ \\
\hline 3D (OBS 1) & 26 & $4 \cdot 1 \%$ & $1 \cdot 3 \%$ & $16 \cdot 4 \%$ \\
3D (OBS 2) & 26 & & $0 \cdot 7 \%$ & $15 \cdot 2 \%$ \\
2D (OBS 1) & 19 & $7 \cdot 0 \%$ & $2 \cdot 7 \%$ & $24 \cdot 2 \%$ \\
2D (OBS 2) & 19 & & $4 \cdot 4 \%$ & $27 \cdot 8 \%$ \\
\hline
\end{tabular}

OBS 1 , observer one; OBS 2 , observer two; $2 \mathrm{D}$, cross sectional echo (biplane summation of discs method); 3D, three dimensional echocardiography. reversal pulse sequences. Slice thickness was $10 \mathrm{~mm}$, and the interslice gap was $1 \mathrm{~mm}$. The entire heart was scanned in two to three fourslice acquisitions, requiring between 20 and 45 min. For each image, the perimeters of the ventricular cavity were traced using an off-line trackball algorithm. The end diastolic image was obtained 8-12 ms after the electrocardiographic $\mathbf{R}$ wave. The end systolic frame was that with the smallest ventricular cavity area. Ventricular end diastolic and end systolic volumes $^{7}$ were computed by summing the ventricular cavity volume over all slices.

\section{CROSS SECTIONAL ECHOCARDIOGRAPHY}

Echocardiograms were obtained with the patient in the supine or left lateral decubitus position, with conventional cross sectional echocardiographic machines using 3 or 5 MHZ transducers (Acuson 128XP or Hewlett Packard 1500 Ultrasound System). In 19 patients with adequate echocardiographic views the apical two-chamber and four-chamber views were used to calculate end diastolic and end systolic volumes according to the apical biplane summation of discs algorithm recommended by the American Society of Echocardiography. ${ }^{26}$ End diastolic (largest ventricular dimension) and end systolic (smallest ventricular dimension) video frames were selected, digitised, and traced by two independent blinded observers using a dimension analyser (Hewlett Packard 1500 Ultrasound System). The border tracing convention applied was the same as that used for analysis of three dimensional echocardiographic images.

\section{STATISTICAL ANALYSIS}

Volumes and ejection fraction determined by each echocardiographic observer were compared to MRI by Pearson's correlation and simple linear regression. The Bland-Altman procedure for comparing two methods was also used to determine the bias (mean difference between two methods) and the limits of agreement (two standard deviations of the difference). ${ }^{27}$ Interobserver variability was expressed as the standard deviation of the differences between measurements and as a percentage of the mean value for a particular variable.

\section{Results}

VOLUME COMPARISON

Three dimensional echocardiography and MRI Interobserver variability was $8.3 \%$ of the mean for systolic volumes and $7 \cdot 6 \%$ of the mean for diastolic volumes. Using the averaged values of both observers, three dimensional echocardiography showed excellent correlations with MRI for both end diastolic and end systolic volumes ( $r=0.94$ and 0.87 respectively) with excellent SEE $(8.8 \mathrm{ml}$ and $6.2 \mathrm{ml}$ respectively). By agreement analysis, three dimensional echo resulted in consistently lower volumes than those obtained by MRI. The bias was 6.9 (SD 6.9) $\mathrm{ml}$ for systolic volumes and $16(11 \cdot 2) \mathrm{ml}$ for diastolic volumes. 
Figure 2 Bland-Altman agreement plots for ejection fraction estimation by $3 D$ echo method (left) and cross sectional echo (right).

The longer broken lines represent two standard deviations of the differences between the two techniques and the shorter broken lines represent the mean differences (bias). Three dimensional echocardiography showed less bias $(1 \cdot 1 \%$ v 3.5\%) and more narrow limits of agreement $( \pm 15 \cdot 4 \% v \pm$ $24 \cdot 0 \%$ ). $2 D E$, cross sectional echocardiography; $3 D E$, three dimensional echocardiography; $E F$, ejection fraction; $M R I$ magnetic resonance imaging.

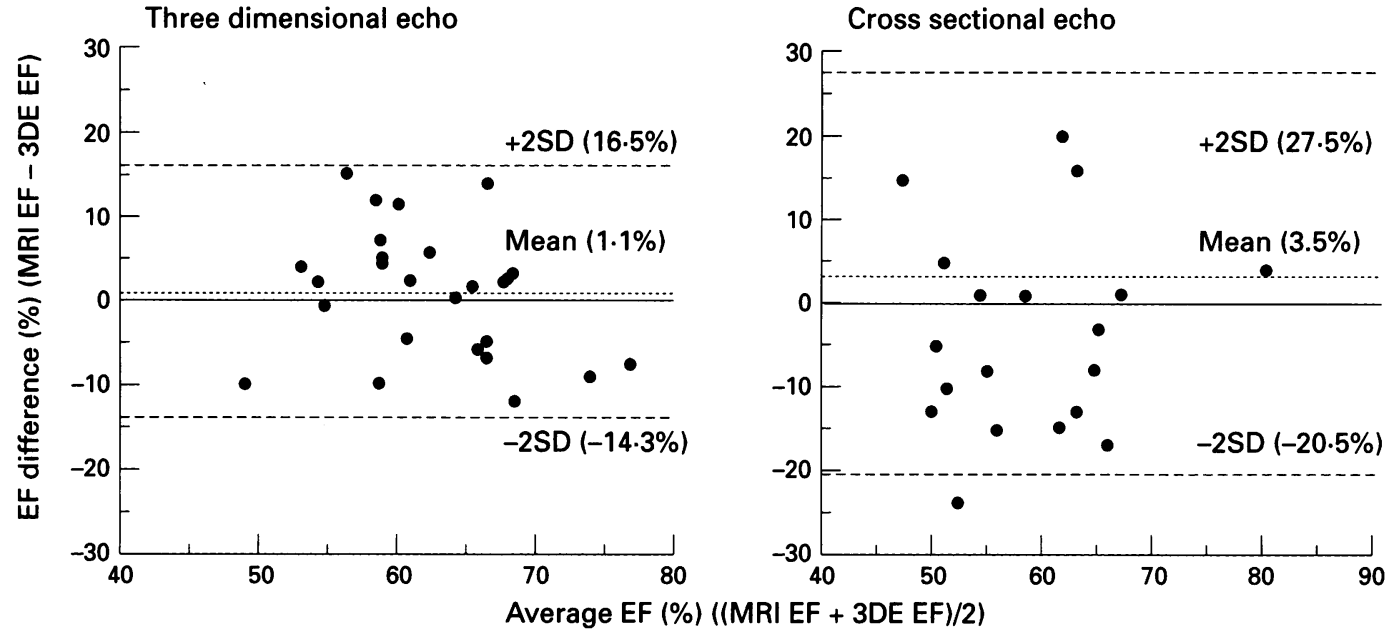

Cross sectional echocardiography

Interobserver variability was significantly higher for the various cross sectional techniques than for three dimensional echocardiography $(32.8 \%$ and $36.3 \%$ for systolic and diastolic volumes respectively). When comparison was made using the best results of the two observers only, cross sectional echocardiography showed poorer correlation, greater SEE, and worse agreement for both end diastolic and end systolic volumes than three dimensional echocardiography $[r=0.62, \mathrm{SEE}=$ $14.2 \mathrm{ml}$, and bias $=3 \cdot 1(14 \cdot 1) \mathrm{ml}$ for systolic volumes; and $r=0.80, \mathrm{SEE}=18.5 \mathrm{ml}$, and bias $=16 \cdot 3(18 \cdot 3) \mathrm{ml}$ for diastolic volumes]. Values for correlation coefficient, SEE, bias, and limits of agreement for each observer for systolic and diastolic volumes for the cross sectional and three dimensional echocardiographic techniques are given in table 1 .

\section{EJECTION FRACTION COMPARISON}

Bias and limits of agreement for each observer for both echocardiographic methods compared to MRI are given in table 2. For two observers, the mean difference between MRI and three dimensional echocardiography was $1 \cdot 1(7 \cdot 7) \%$. For the cross sectional technique the corresponding value was $3.5(12.0) \%$. Figure 2 shows limits of agreement plots for each echocardiographic method.

\section{Discussion}

While cross sectional echocardiography is an attractive imaging method, standard methods are of limited use for volume and functional quantitation. ${ }^{1-6}$ As demonstrated here, agreement is particularly poor in patients with distorted ventricles where standard geometric assumptions become tenuous..$^{4-6}$

Three dimensional echocardiography has been shown in several studies to be comparable to MRI and radionuclide angiography in the assessment of normally shaped left ventricles. ${ }^{2025}$ Volume and functional quantitation in patients with severely deformed ventricular geometry, however, has not been done. Because it eliminates geometric assumptions and image plane positioning errors, we hypothesised that three dimensional echocar- diography would compute volumes in nonellipsoid left ventricles with the same degree of accuracy shown in non-distorted left ventricles. Our study supports that contention in a select group of patients with compressed left ventricles secondary to right ventricular hypertension. Furthermore, interobserver variability for three dimensional echocardiography (approximately $8.0 \%$ ) was comparable to values previously reported for magnetic resonance imaging $(5 \cdot 7 \%$ to $7 \cdot 1 \%){ }^{7}$

FEASIBILITY OF THREE DIMENSIONAL ECHOCARDIOGRAPHY IN THE PAEDIATRIC POPULATION

Most of the patients studied (65\%) were less than 13 years of age. Potential problems related to three dimensional echocardiographic techniques that warrant special consideration in this population include the need for minimal patient motion and sedation and the effects of heart rate and respiratory rate on data acquisition. In the present study there was no more need for sedation for the three dimensional technique than for the conventional cross sectional examinations (two patients, ages 2 and 3 years). This may not have been the case if a greater number of patients younger than three years of age had been studied. Furthermore, relatively fast heart and respiratory rates did not seem to affect the accuracy of our technique in children. This too may not be true in the infant age range, where heart and respiratory rates are greatest. Further work in the infant age group should lead to optimisation of reference and real time images using variable echocardiographic windows and modification of imaging protocols depending on the situs of the patient and congenital anomaly present.

\section{STUDY LIMITATIONS AND LIMITATIONS OF} THREE DIMENSIONAL ECHOCARDIOGRAPHY On clinical studies it is often difficult to image the left ventricular apex adequately from the parasternal window. Although we attempted to overcome this problem by incorporating a second reference image that maximises the apical segments it is possible that foreshortening in this area resulted in some loss of chamber volume. 
Boundary tracing is time consuming and relatively labour intensive. Furthermore, tracing inaccuracies remains a significant potential source of error with all imaging methods. These errors in cross sectional echocardiographic systems (as also employed in our three dimensional system) are caused primarily by inadequate definition of the boundary and by relatively poor lateral resolution of the ultrasound beam within the image plane and perpendicular to it. While satisfactory accuracy and reproducibility can be achieved by careful adherence to a well defined rule for tracing, precise boundary tracing remains a difficult problem.

Finally, the fact that the methodologies assessed in this study were not performed simultaneously but as much as several days apart raises the possibility that volume differences noted may have been exaggerated by altered loading conditions at different points in time.

\section{CONCLUSION}

The results of this study show that three dimensional echocardiography, using the polyhedral surface reconstruction algorithm and the line of intersection display for image positioning guidance, provides reliable estimates of left ventricular volumes and ejection fraction, comparable to magnetic resonance imaging in patients with compressed left ventricular geometry secondary to pulmonary hypertension. Furthermore, three dimensional echocardiography is more accurate and reproducible in these patients than conventional cross sectional echocardiography.

This study was supported in part by a grant-in-aid award from the American Heart Association, NY City affiliate. Dr Apfel is the recipient of a grant from the Hatch Young Investigators Fund for Cardiovascular Training.

1 Naik MM, Diamond GA, Pai T, Soffer A, Siegel RJ. Correspondence of left ventricular ejection fraction determinations from two-dimensional echocardiography radionuclide angiography, and contrast cineangiography. $f$ Am Coll Cardiol 1995;25:937-42.

2 Silverman NH, Ports TA, Snider AR, Schiller NB, Carlsson E, Heilbaum DC. Determination of left ventricular volume in children: echocardiographic and angiographic comparisons. Circulation 1980;62:548-57.

3 Mercier JC, DiSssa TG, Jarmakani JM. Two-dimensional echocardiographic assessment of left ventricular volumes and ejection fraction in children. Circulation 1982;65 and ejectic

4 Wyatt HL, Meerbaum S, Heng MK, Gueret P, Hestness J, Cordey E. Cross sectional echocardiograph. III. Analysi of mathematical models for quantifying volume of symmetric and asymmetric left ventricles. Am Heart $\mathcal{F} 1980$ 10:821-8.

5 Folland ED, Parisi AF, Maynihan BS, Jones DR, Felman $\mathrm{CL}$, Tow DE. Assessment of left ventricular ejection fraction and volumes by real-time two-dimensional echocardiography. A comparison of cineangiographic and radioniclide techniques. Circulation 1979;60:760-6.

6 Helak JW, Reichek N. Quantitation of human left ventricular mass and volume by two-dimensional echocardiography. In vit

7 Boxt LM, Katz J, Kolb T, Czegledy F, Barst RJ. Direct quantitation of right and left ventricular volumes with quantitation of right and left ventricular volumes with
nuclear magnetic resonance imaging in patients with pri- mary pulmonary hypertension. F Am Coll Cardiol 1988;9: 529-33.

8 Shapiro EP, Rogers WJ, Beyar R. Determinations of left ventricular mass by magnetic resonance imaging in hearts deformed by acute infarction. Circulation 1989;79. 706-11.

9 Higgins CB. Which standard has the gold? $f \mathrm{Am}$ Coll Cardiol 1992;19:1608-9.

10 Handschumacher MD, Lethor JP, Siu SC, Picerd MH, Weyman AE, Levine RA. A new integrated system for three-dimensional echocardiographic reconstruction: development and validation for ventricular volumetion: application in human subjects. $\mathcal{F}$ Am Coll Cardiol 1993; 21:743-53.

11 Geiser EA, Ariet M, Conetta DA, Lupkiewicz SM, Christie LG, Conti CR. Dynamic three-dimensional echocardiographic reconstruction of the intact human left ventricle: technique and initial observation in patients. Am Heart $\mathscr{f}$ 1982;103:1056-65.

12 McPherson DD, Skorton DJ, Kodiyalam S. Finite element analysis of myocardial diastolic function using threedimensional echocardiographic reconstructions: application of a new method for the study of acute ischemia in dogs. Circ Res 1987;60:674-82.

13 Raichlen JS, Trivedi SS, Herman GT, St John J, Sutton MG, Reichek N. Dynamic three-dimensional reconstruction of the left ventricle from two-dimensional echocardiograms. F Am Coll Cardiol 1986;8:364-70.

14 Ghosh A, Nanda NC, Maurer G. Three-dimensional reconstruction of echocardiographic images using the reconstruction of echocardiographic images using the

15 Pearlman AS, Moritz WE, Medema DK. Reproducible measurement of ventricular volume by three-dimensional echocardiographic reconstruction. Am $\mathcal{F}$ Cardiol 1984;49 896-902.

16 Martin RW, Bashein G. Measurement of stroke volume with three-dimensional transesophageal ultrasonic scanning. Anesthesiology 1989;70:470-6.

17 King DL, Al-Banna SJ, Larach DL. A new, three-dimensional random scanner for ultrasonic/computergraphic imaging of the heart. In: White DN, Barnes R, eds. Ultrasound in Medicine. New York: Plenum, 1976: 363-6.

18 King DL, King DL, Shao MYC. Three-dimensional spatial registration and interactive display of position and orientation of real-time ultrasound images. $₹$ Ultrasound Med 1990;9:525-32.

19 King DL, King DL, Shao MYC. Evaluation of in-vitro measurement accuracy of a three-dimensional ultrasound canner. F Ultrasound Med 1991;10:77-82.

20 Gopal AS, Shen Z, Sapin PM, Keller AM, Schnellbacche MJ, Leibowitz DW, et al. Assessment of cardiac function by three-dimensional echocardiography compared to conventional non-invasive methods. Circulation 1995;92 842 .

21 Vogel M, Pandian N, Marx G, Ludomirsky A, Delabays A. Transthoracic real-time three-dimensional echocardiography in 100 pediatric and adult patients with heart disease: clinical utility of unique new views unavailable in two-dimensional echocardiography. Circulation 1993;88. I-349.

22 Marx G, Vogel M, Pandian N, Cao A, Ludomirsky A, Delabays A, et al. Delineation of the site, size, shape and dynamic geometry of atrial septal defects by real-time three-dimensional echocardiography using a tomographic ultrasound approach in in- and out-patients. Circulation 1993;88:I-409.

23 Marx GR, Fulton DR, Pandian NG, Vogel M, Cao A, Ludomirsky A, et al. Delineation of site, relative size and dynamic geometry of atrial septal defects by real-time three-dimensional echocardiography. $\mathcal{F} \mathrm{Am}$ Coll Cardiol 1995;25:482-90.

24 Vogel M, Losch S. Dynamic three-dimensional echocardiography with a computed tomography imaging probe: initial clinical experience with transthoracic application in infants and children with congenital heart defects. $B r$ Heart ₹ 1994;71:462-7.

25 Gopal AS, Keller AM, Rigling R, King DL, King DL. Left ventricular volume and endocardial surface area by threedimensional echocardiography: comparison to twodimensional echocardiography and magnetic resonance imaging in normal subjects. $\Im \mathrm{Am}$ Coll Cardiol 1993;22. 258-70.

26 Schiller NB, Shah PM, Crawford M, et al. American Society of Echocardiography. Committee on Standards, Subcommittee on Quantitation of Two-dimensional Echocardiograms. Recommendations for quantitation of the left ventricle by two-dimensional echocardiography. $\mathcal{F}$ Am Soc Echocardiogr 1989;2:356-67.

27 Altman DG, Bland JM. Measurement in medicine: the analysis of method comparison studies. Statistician 1983; 32:307-17. 